\title{
Effect of genistein on myocardial fibrosis in diabetic rats and its mechanism
}

\author{
RUI YANG ${ }^{*}$, QIANG JIA* ${ }^{*}$ XIAO-FEN LIU and SHAN-FENG MA \\ Department of Physiology, Bengbu Medical College, Bengbu, Anhui 233030, P.R. China
}

Received August 16, 2017; Accepted December 6, 2017

DOI: $10.3892 / \mathrm{mmr} .2017 .8268$

\begin{abstract}
The aim of the present study was to investigate the effects of genistein (GEN) on myocardial fibrosis in type 1 diabetic rats and explore the underlying mechanisms. Rats were divided into 4 groups: Normal control $(\mathrm{N})$, diabetic control (D), low-dose GEN treatment (L) and high-dose GEN treatment $(\mathrm{H})$ groups. Following 8 weeks, the ventricular hemodynamic parameters, fasting blood glucose (FBG), heart-weight to body-weight ratio ( $\mathrm{HW} / \mathrm{BW})$, myocardial hydroxyproline (Hyp) content, serum creatine kinase $\mathrm{MB}$ isozyme (CK-MB), lactate dehydrogenase (LDH), tumor necrosis factor- $\alpha$ (TNF- $\alpha)$, interleukin-1 $\beta$ (IL-1 $\beta$ ) and interleukin-6 (IL-6) levels were measured. The histomorphology and ultrastructure of the heart were observed. The protein expression of myocardial transforming growth factor- $\beta 1$ (TGF- $\beta 1$ ), mothers against decapentaplegic homolog (Smad)-3, phosphorylated (p)-Smad3, Smad4, collagen-I and collagen-III were estimated. Compared with the $\mathrm{N}$ group, while the cardiac function was decreased, the levels of FBG, HW/BW, Hyp content, CK-MB, LDH, TNF- $\alpha$, IL-1 $\beta$ and IL- 6 were increased in the $\mathrm{D}$ group. The myocardial histomorphological alterations and ultrastructure were damaged, and the protein expression of myocardial TGF- $\beta 1$, Smad3, p-Smad3, Smad4, collagen-I and collagen-III were increased in the D group. Compared with the $\mathrm{D}$ group, there were no differences in the ventricular hemodynamic parameters, FBG and p-Smad3 expression in the L group, while HW/BW, Hyp content, CK-MB, LDH, TNF- $\alpha$, IL-1 $\beta$ and IL- 6 levels were decreased. The myocardial histomorphological damage was alleviated and the protein expression of TGF- $\beta 1$, Smad3, Smad4, collagen-I and collagen-III was decreased in the L group. Compared with
\end{abstract}

Correspondence to: Dr Shan-Feng Ma, Department of Physiology, Bengbu Medical College, 2600 Dong Hai Avenue, Bengbu, Anhui 233030, P.R. China

E-mail: msfbio@163.com

*Contributed equally

Key words: genistein, diabetes mellitus, rat, myocardial fibrosis, transforming growth factor- $\beta 1 /$ mothers against decapentaplegic homolog 3
L group, excluding FBG, the aforementioned indices were improved in the $\mathrm{H}$ group. In conclusion, GEN can attenuate myocardial fibrosis in type 1 diabetic rats, and the underlying mechanisms may be associated with the reduction of CK-MB and LDH leakage, inhibition of the inflammatory reaction, and suppression of the TGF- $\beta 1 / \mathrm{Smad} 3$ signaling pathway to regulate collagen expression.

\section{Introduction}

Diabetes mellitus is one of the major public health problems around the world (1). According to the compiled data of the International Diabetes Federation, $\sim 1$ in 11 adults has diabetes mellitus worldwide, and the number of diabetic patients may reach 642 million by the year 2040 .

Diabetic cardiomyopathy (DCM) is defined as the ventricular dysfunction in diabetic patients which do not rely on some causes, coronary artery disease, hypertension and so on. DCM is one of the main cardiovascular complications of diabetes which has become a major cause of morbidity and mortality in diabetic patients $(2,3)$. Interstitial fibrosis is a histological hallmark of DCM $(4,5)$.

The normal structure of heart is composed of several different cell types such as cardiomyocytes, cardiac fibroblasts, endothelial cells, smooth muscle cells and extracellular matrix (ECM) including collagens, larninin and fibrinogen $(6,7)$. Excessive deposition of ECM is one of the important pathological alterations in diabetic hearts (8). Interstitial collagens such as collagen-I and collagen-III are the major components of ECM in heart, which play important roles in supporting and protecting cardiomyocytes and maintaining the normal structure and function of myocardial tissue ingredient. The excess production of collagen-I and collagen-III proteins may be responsible for myocardial interstitial collagen deposition, disorder, and even heart damage (9). An abnormal amount of collagen increases the hardness of the myocardium and reduces the diastolic function of the heart. With the increase of myocardial fibrosis, the myocardial systolic function is also damaged.

The isoflavone genistein (GEN; 4',5,7-trihydroxyisoflavone), which is known to interact with estrogen receptors and has weak estrogenic activity, is a phytoestrogen found at high levels in soy products $(10,11)$. Studies have demonstrated that GEN plays a critical role in anti-inflammatory, anti-oxidative and anti-proliferation effects $(12,13)$. Recent research has 
shown that GEN can reduce cardiac inflammation and oxidative stress in DCM (14). GEN can also protect the liver from chronic injury in D-galactosamine-induced liver fibrosis by inhibiting accumulation of the collagen matrix, suppressing the expression of transforming growth factor- $\beta$ (TGF- $\beta$ ) and activation of the TGF- $\beta /$ Smad signaling pathway (15). However, it is not clear whether the TGF- $\beta / \mathrm{Smad}$ pathway is involved in the cardioprotective effect of GEN on myocardial fibrosis in diabetic rats. The purpose of the present study was to investigate the effects of GEN on myocardial fibrosis in type 1 diabetic rats and to elucidate the underlying mechanisms. This study may shed some light on GEN as a novel effective medicine in treating DCM.

\section{Materials and methods}

Animals. Male Sprague-Dawley rats (6-7 weeks of age, 160-200 g) were obtained from of Bengbu Medical College Animal Administration Center. The rats were given free access to normal diet and water, and housed in cages at room temperature $\left(22 \pm 1^{\circ} \mathrm{C}\right)$ with a fixed $12 \mathrm{~h}$ light/dark cycle. All animal experiments were approved by the Animal Ethics Committee of Bengbu Medical College and conducted in accordance with ethical standards.

Chemicals and reagents. Streptozotocin and GEN were purchased from Sigma-Aldrich (St. Louis, MO, USA). Carboxymethylcellulose sodium (CMC-Na) was purchased from Shanghai Sangon Biological Engineering Co., Ltd., (Shanghai, China). Hydroxyproline (Hyp), creatine kinase MB isozyme (CK-MB), lactate dehydrogenase (LDH), tumor necrosis factor- $\alpha$ (TNF- $\alpha$ ), interleukin-1 $\beta$ (IL-1 $\beta$ ) and interleukin-6 (IL-6) assay kits were purchased from Nanjing Jiancheng Bioengineering Institute (Nanjing, Jiangsu, China). Bradford and bicinchoninic acid (BCA) protein assay kits were purchased from Beyotime Biotechnology (Shanghai, China). Rabbit TGF- 31 , Smad3, phospho-Smad3 (p-Smad3) and Smad4 antibodies were purchased from Abcam (Cambridge, MA, USA). Rabbit collagen-I and collagen-III antibodies were purchased from Boster Biological Technology (Wuhan, Hubei, China). Rabbit $\beta$-actin antibody was purchased from Proteintech Group (Wuhan, Hubei, China). Goat anti-rabbit secondary antibody was purchased from Biosharp Biotechnology (Hefei, Anhui, China).

Induction of diabetes and experimental protocol. All rats were divided randomly into 4 groups: Normal control group (N), diabetic control group (D), low-dose GEN treatment group (L) and high-dose GEN treatment group $(\mathrm{H})(n=8)$. Type 1 diabetes mellitus was induced in overnight fasted rats by administering a single intraperitoneal injection of $55 \mathrm{mg} / \mathrm{kg}$ streptozotocin freshly dissolved in $0.1 \mathrm{~mol} / 1$ sodium citrate buffer ( $\mathrm{pH} 4.5$ ). The rats in the $\mathrm{N}$ group were received an intraperitoneal injection with the same volume of sodium citrate buffer. The rats with plasma fasting blood glucose (FBG) level $>16.7 \mathrm{mmol} / \mathrm{l}$ (72 $\mathrm{h}$ after injection) were considered as type 1 diabetic rats. The FBG level was monitored once a week during the experimental period. After successful building models, from the fifth week, the rats in the $\mathrm{L}$ and $\mathrm{H}$ groups were daily gavaged with 5 and $25 \mathrm{mg} / \mathrm{kg}$ GEN solution (freshly dissolved in CMC-Na) for 4 weeks, respectively. The doses of GEN were chosen according to a method reported (16). The rats in the $\mathrm{N}$ and $\mathrm{D}$ groups were daily gavaged with the same volume of CMC-Na for 4 weeks.

Ventricular hemodynamic measurements. Rats were anaesthetized by intraperitoneal injection with chloral hydrate $(100 \mathrm{mg} / \mathrm{kg})$ and performed trachea cannula. Right carotid artery was separated and intubated to the left ventricle. Left ventricular systolic pressure (LVSP), left ventricular end-diastolic pressure (LVEDP) and maximal rise/fall rate of left ventricular pressure $\left( \pm d p / d t_{\max }\right)$ were recorded by the Med-Lab Biological Recording system (Medease Company, Nanjing, China).

Detection of FBG level, body-weight $(B W)$, heart-weight $(H W)$ and $H W / B W$. After ventricular hemodynamic measurement, the blood was collected and FBG level was measured. Rats were sacrificed and their hearts were excised rapidly to place in ice-cold normal saline, and HW/BW was calculated.

Determination of myocardial Hyp content. Heart tissue $(0.1 \mathrm{~g})$ was homogenized in $0.9 \mathrm{ml}$ ice-cold normal saline. The supernatant was collected after centrifugation for $20 \mathrm{~min}$ $(3,000 \mathrm{rpm} / \mathrm{min})$. The protein concentration was measured by the Bradford protein assay kit. Hyp content was measured according to the instruction manual.

Determination of serum $C K-M B, L D H, T N F-\alpha, I L-1 \beta$ and IL-6 levels. The blood was placed in centrifuge tubes and centrifuged at 3,000 $\mathrm{rpm} / \mathrm{min}$ for $20 \mathrm{~min}$. The supernatant was collected. CK-MB, LDH, TNF- $\alpha$, IL-1 $\beta$ and IL- 6 levels were measured using the corresponding assay kits according to kit instructions.

Histomorphological observation by hematoxylin and eosin (H\&E) staining and Masson's trichrome staining. Fresh myocardial tissue was fixed in $4 \%$ paraformaldehyde, embedded in paraffin, and cut into $5 \mu \mathrm{m}$ thick serial sections. After de-waxed, the sections were stained with H\&E and Masson's trichrome, respectively.

Ultrastructure observation under transmission electron microscope. Fresh myocardial tissues were cut into the size of $1 \times 1 \times 1 \mathrm{~mm}$, fixed in ice-cold $2.5 \%$ glutaraldehyde for $2 \mathrm{~h}$, and post-fixed in $1 \%$ osmium tetroxide for $1 \mathrm{~h}$. Ultrathin sections stained with uranyl acetate and lead citrate were observed with JEM-1230 transmission electron microscope (JEOL, Tokyo, Japan).

Detection of TGF- $\beta 1$, Smad3, p-Smad3, Smad4, collagen-I and collagen-III protein by western blot analysis. Myocardial tissue $(0.1 \mathrm{~g})$ was collected and homogenized in $1 \mathrm{ml}$ protein extraction buffer ( $990 \mu \mathrm{l}$ lysis buffer $+10 \mu \mathrm{l}$ Phenylmethanesulfonyl fluoride). The supernatant was collected and protein concentration was measured using the BCA protein assay kit. Proteins $(50 \mu \mathrm{g})$ were separated using sodium dodecyl sulfate-polyacrylamide gel electrophoresis and transferred onto polyvinylidene difluoride membranes. Membrane with p-Smad3 was blocked in Tris buffered saline Tween-20 

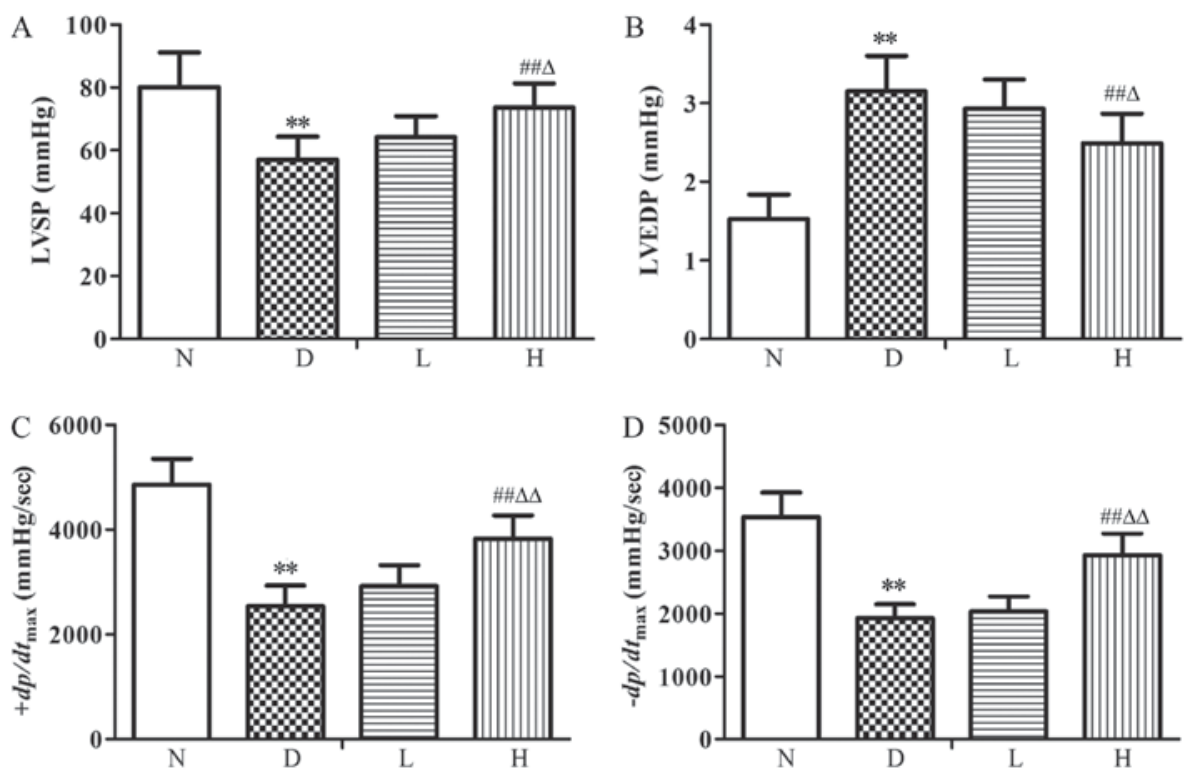

Figure 1. Ventricular hemodynamic parameters in the different groups. (A) LVSP, (B) LVEDP, (C) $+d p / d t_{\max }$ and (D)- $d p / d t_{\max }$. Data were expressed as the mean \pm standard deviation $(\mathrm{n}=8)$. ${ }^{* * *} \mathrm{P}<0.01$ vs. $\mathrm{N}$ group; ${ }^{* \#} \mathrm{P}<0.01$ vs. $\mathrm{D}$ group; ${ }^{\Delta} \mathrm{P}<0.05$ and ${ }^{\Delta \wedge} \mathrm{P}<0.01$ vs. $\mathrm{L}$ group. $\mathrm{N}$, normal control group; $\mathrm{D}$, diabetic control group; L, low-dose genistein treatment group; H, high-dose genistein treatment group; LVSP, left ventricular systolic pressure; LVEDP, left ventricular end diastolic pressure; $+d p / d t_{\max }$, maximal rise rate of left ventricular pressure; $-d p / d t_{\max }$, maximal fall rate of left ventricular pressure.

(TBST) containing 5\% bovine serum albumin, and membranes with TGF- $\beta 1$, Smad3, Smad4, collagen-I, collagen-III and $\beta$-actin were blocked in TBST containing 5\% nonfat milk at $37^{\circ} \mathrm{C}$ for $2 \mathrm{~h}$, and then they were incubated overnight at $4^{\circ} \mathrm{C}$ with the following primary antibodies: Anti-TGF- $\beta 1(1: 1,000)$, anti-Smad3 (1:1,000), anti-p-Smad3 (1:1,000), anti-Smad4 $(1: 1,000)$, anti-collagen-I (1:400), anti-collagen-III (1:400) and anti- $\beta$-actin $(1: 2,000)$. Membranes were then washed with TBST and incubated with a horseradish peroxidase conjugated goat anti-rabbit IgG secondary antibody for $1 \mathrm{~h}$ at room temperature. Autoradiographs were scanned with ChemiDoc XRS system (Bio-Rad, Berkeley, CA, USA) and the band density was determined with Quantity One software.

Statistical analysis. Data were expressed as mean \pm SD. Statistical comparisons were performed by one-way analysis of variance and the Newman-Keuls test. $\mathrm{P}<0.05$ was considered to indicate a statistically significant difference.

\section{Results}

Changes of ventricular hemodynamic parameters. Compared with the $\mathrm{N}$ group, LVSP and $\pm d p / d t_{\max }$ were decreased $(\mathrm{P}<0.01)$ significantly, while LVEDP was increased $(\mathrm{P}<0.01)$ significantly in the D group; Compared with the D group, there were no statistical differences in ventricular hemodynamic parameters in the L group; LVSP and $\pm d p / d t_{\max }$ were increased $(\mathrm{P}<0.01)$ significantly, LVEDP was decreased $(\mathrm{P}<0.01)$ in the $\mathrm{H}$ group. Compared with the $\mathrm{L}$ group, LVSP and $\pm d p / d t_{\max }$ were increased $(\mathrm{P}<0.05, \mathrm{P}<0.01)$, while LVEDP was decreased $(\mathrm{P}<0.05)$ in the $\mathrm{H}$ group (Fig. 1).

Changes of $F B G, B W, H W, H W / B W$ and Hyp content. Compared with the N group, BW and HW were decreased $(\mathrm{P}<0.01)$, while FBG, HW/BW and Hyp content were significantly increased
$(\mathrm{P}<0.01)$ in the $\mathrm{D}$ group. Compared with the $\mathrm{D}$ group, there were no statistical differences in FBG and $\mathrm{HW}$ in the L group, BW was increased $(\mathrm{P}<0.05)$, while $\mathrm{HW} / \mathrm{BW}$ and Hyp content were decreased $(\mathrm{P}<0.05)$; in the $\mathrm{H}$ group, there was no statistical difference in FBG, while BW and $\mathrm{HW}$ were increased $(\mathrm{P}<0.01)$, HW/BW and Hyp content were significantly decreased $(\mathrm{P}<0.01)$. Compared with the $\mathrm{L}$ group, BW and $\mathrm{HW}$ were increased $(\mathrm{P}<0.01)$, while $\mathrm{HW} / \mathrm{BW}$ and Hyp content were decreased $(\mathrm{P}<0.05, \mathrm{P}<0.01)$ in the $\mathrm{H}$ group (Table I).

Changes of serum CK-MB, LDH, TNF- $\alpha, I L-1 \beta$ and $I L-6$ levels. Compared with the $\mathrm{N}$ group, serum CK-MB, LDH, TNF- $\alpha$, IL- $1 \beta$ and IL-6 levels were increased $(\mathrm{P}<0.01)$ in the D group; Compared with the D group, CK-MB, LDH, TNF- $\alpha$, IL-1 $\beta$ and IL-6 levels were decreased $(\mathrm{P}<0.05, \mathrm{P}<0.01)$ in the L group; CK-MB, LDH, TNF- $\alpha$, IL-1 $\beta$ and IL-6 levels were decreased $(\mathrm{P}<0.01)$ in the $\mathrm{H}$ group. Compared with the L group, CK-MB, LDH, TNF- $\alpha$, IL-1 $\beta$ and IL-6 levels were decreased $(\mathrm{P}<0.01)$ in the $\mathrm{H}$ group (Fig. 2).

Histological changes in myocardial tissue by $H \& E$ staining. In the $\mathrm{N}$ group, the myocardial fibers were arranged in neat rows, the myocardial nuclei were clear, the myocardial gap was normal and inflammatory cells soak was rare. In the D group, the myocardial fibers were disordered, the cardiomyocytes were swollen significantly and myocardial gap was widened. Inflammatory cells were infiltrated significantly and the distribution of cytoplasm was uneven in the D group. Compared with the D group, the myocardial damage in the L group was relatively ameliorated, however, the arrangement of myocardial fibers was disordered and inflammatory cell infiltration was observed. The myocardial damage in the $\mathrm{H}$ group was obviously ameliorated, most of the myocardial cells were arranged neatly and the infiltration of inflammatory cells was significantly reduced (Fig. 3). 
Table I. Fasting blood glucose, body and heart weight and the ratio, and hydroxyproline content in the different groups .

\begin{tabular}{|c|c|c|c|c|c|}
\hline Group & FBG (mmol/l) & $\mathrm{BW}(\mathrm{g})$ & HW (mg) & HW/BW (mg/g) & Нур $(\mu \mathrm{g} / \mathrm{mg})$ \\
\hline $\mathrm{N}$ & $5.54 \pm 0.87$ & $443.90 \pm 31.23$ & $1,261.27 \pm 136.97$ & $2.89 \pm 0.24$ & $3.15 \pm 0.42$ \\
\hline $\mathrm{D}$ & $24.91 \pm 3.23^{\mathrm{a}}$ & $230.50 \pm 26.55^{\mathrm{a}}$ & $811.45 \pm 61.60^{\mathrm{a}}$ & $3.64 \pm 0.29^{\mathrm{a}}$ & $6.83 \pm 0.87^{\mathrm{a}}$ \\
\hline $\mathrm{L}$ & $24.67 \pm 3.40$ & $263.21 \pm 28.17^{\mathrm{b}}$ & $852.02 \pm 63.25$ & $3.35 \pm 0.27^{\mathrm{b}}$ & $5.97 \pm 0.70^{\mathrm{b}}$ \\
\hline $\mathrm{H}$ & $21.86 \pm 3.02$ & $359.28 \pm 29.38^{c, e}$ & $1,078.64 \pm 119.86^{\mathrm{cee}}$ & $3.02 \pm 0.25^{\mathrm{c}, \mathrm{d}}$ & $4.52 \pm 0.66^{\mathrm{c}, \mathrm{e}}$ \\
\hline
\end{tabular}

Data were expressed as the mean \pm standard deviation $(\mathrm{n}=8) .{ }^{\mathrm{a}} \mathrm{P}<0.01$ vs. $\mathrm{N}$ group; ${ }^{\mathrm{b}} \mathrm{P}<0.05$ and ${ }^{\mathrm{c}} \mathrm{P}<0.01$ vs. $\mathrm{D}$ group; ${ }^{\mathrm{d}} \mathrm{P}<0.05$ and ${ }^{e} \mathrm{P}<0.01$ vs. L group. $\mathrm{N}$, normal control group; $\mathrm{D}$, diabetic control group; L, low-dose genistein treatment group; H, high-dose genistein treatment group; FBG, fasting blood glucose; BW, body-weight; HW, heart-weight; HW/BW, heart-weight to body-weight ratio; Hyp, hydroxyproline.
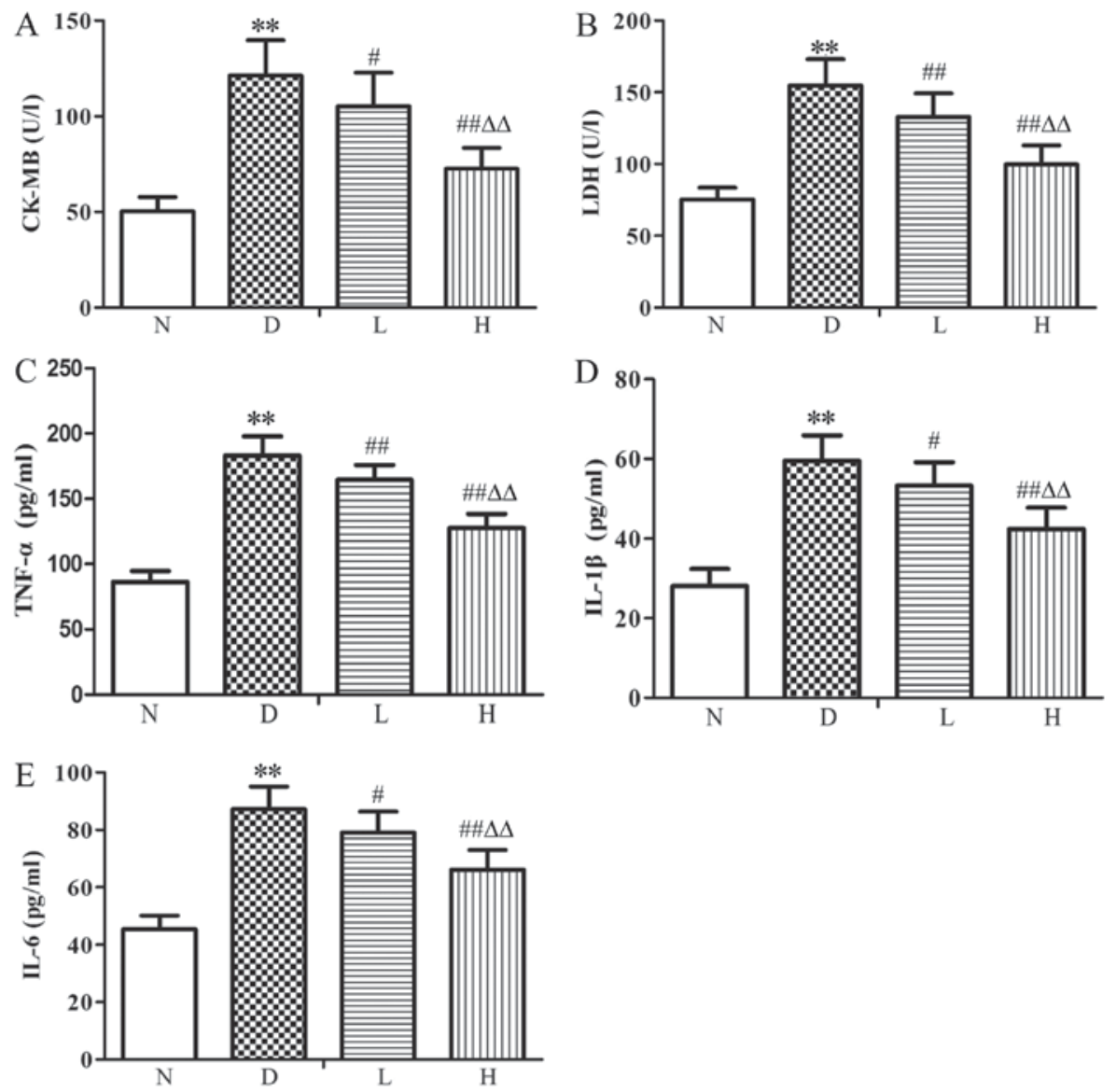

Figure 2. Levels of (A) CK-MB, (B) LDH, (C) TNF- $\alpha$, (D) IL-1 $\beta$ and (E) IL-6 in the serum of the different groups. Data were expressed as the mean \pm standard deviation $(\mathrm{n}=8) .{ }^{* * *} \mathrm{P}<0.01$ vs. $\mathrm{N}$ group; ${ }^{\#} \mathrm{P}<0.05$ and ${ }^{\# \#} \mathrm{P}<0.01$ vs. D group; ${ }^{\Delta \Delta} \mathrm{P}<0.01$ vs. $\mathrm{L}$ group. $\mathrm{N}$, normal control group; $\mathrm{D}$, diabetic control group; $\mathrm{L}$, low-dose genistein treatment group; $\mathrm{H}$, high-dose genistein treatment group; CK-MB, creatine kinase MB isozyme; LDH, lactate dehydrogenase; TNF- $\alpha$, tumor necrosis factor- $\alpha$; IL-1 $\beta$, interleukin-1 $\beta$; IL-6, interleukin-6.

The morphology of collagen detection by Masson's trichrome staining. In Masson's trichrome staining, the collagen fibers were stained blue and cardiomyocytes were stained red. In the $\mathrm{N}$ group, the myocardial fibers were arranged in neat row and the myocardial gap was normal. The interstitial collagen fibers were rare. In the D group, the cardiomyocytes were in a disordered arrangement, the myocardial gap was widened and the interstitial collagen fibers were increased obviously. Treated with GEN, the cardiomyocytes were disrupted in some areas and collagen fibers were decreased slightly in the L group; in the $\mathrm{H}$ group, the cardiomyocytes were approximately arranged neatly, collagen fibers were sparsely distributed, and interstitial collagen was dyed a little blue (Fig. 4).

Changes in the myocardial ultrastructure. In the $\mathrm{N}$ group, the sarcomeres of the myocardium were arranged orderly and maintained homogenous length; intermyofibrillar mitochondria were arranged in an ordered pattern in myocardium. In the D group, the integrity of the cardiomyocyte was destroyed and mitochondrial matrix was severely damaged. In addition, the collagen fibers were found (shown with black arrows), which indicated the severity of myocardial 

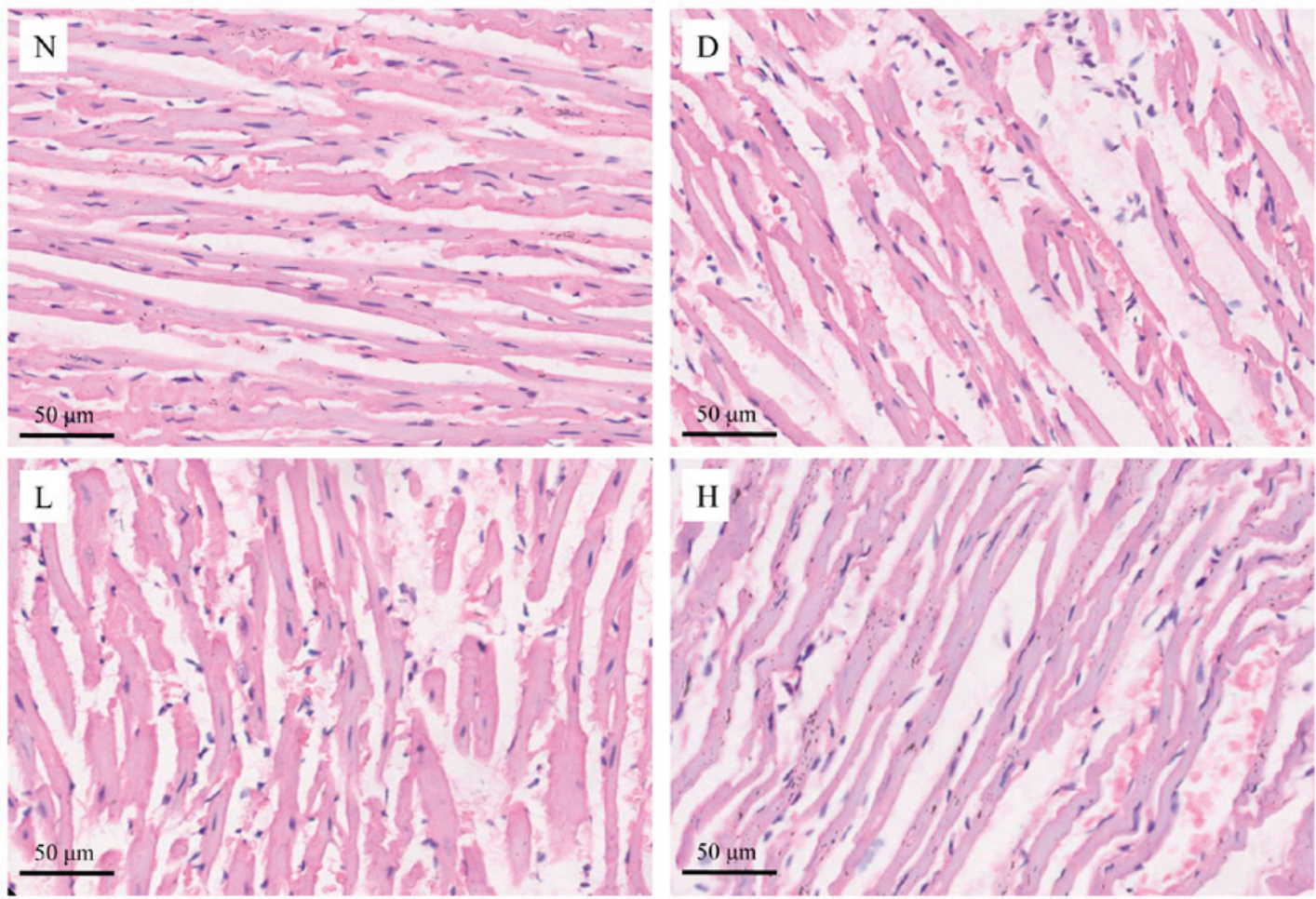

Figure 3. Histological changes of myocardial tissue by hematoxylin and eosin staining in the different groups. N, normal control group; D, diabetic control group; L, low-dose genistein treatment group; $\mathrm{H}$, high-dose genistein treatment group. Scale bar, $50 \mu \mathrm{m}$.
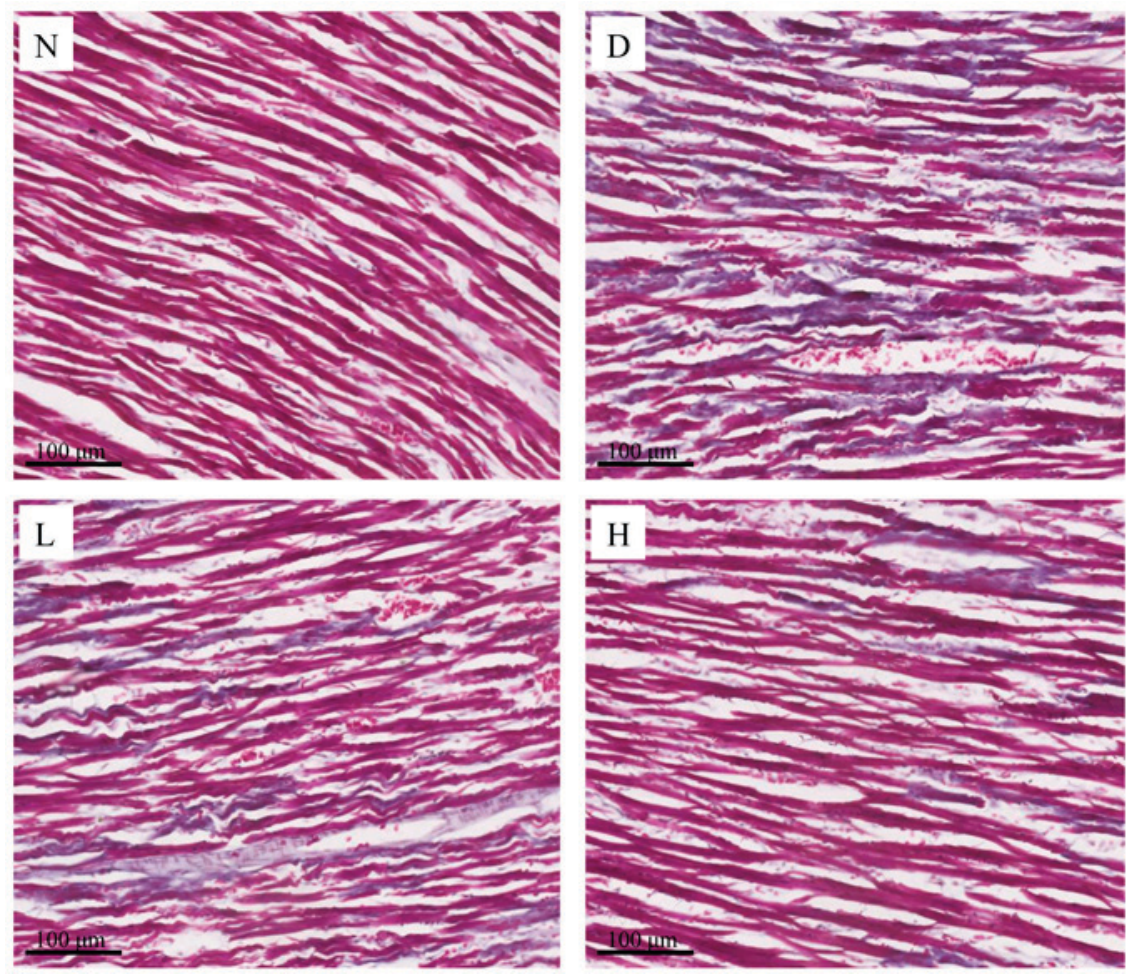

Figure 4. Morphology of myocardial tissue by Masson's trichrome staining in the different groups. N, normal control group; D, diabetic control group; $\mathrm{L}$, low-dose genistein treatment group; $\mathrm{H}$, high-dose genistein treatment group. Scale bar, $100 \mu \mathrm{m}$.

fibrosis. After treatment with GEN, compared with the D group, myocardial injury was alleviated in the L group; these injuries were significantly ameliorated in the $\mathrm{H}$ group (Fig. 5).
Changes in myocardial TGF- $\beta 1$, Smad3, p-Smad3, Smad4, collagen-I and collagen-III at protein levels. Compared with the N group, levels of myocardial TGF- $\beta 1$, Smad3, p-Smad3, p-Smad3/Smad3, Smad4, collagen-I and collagen-III were 

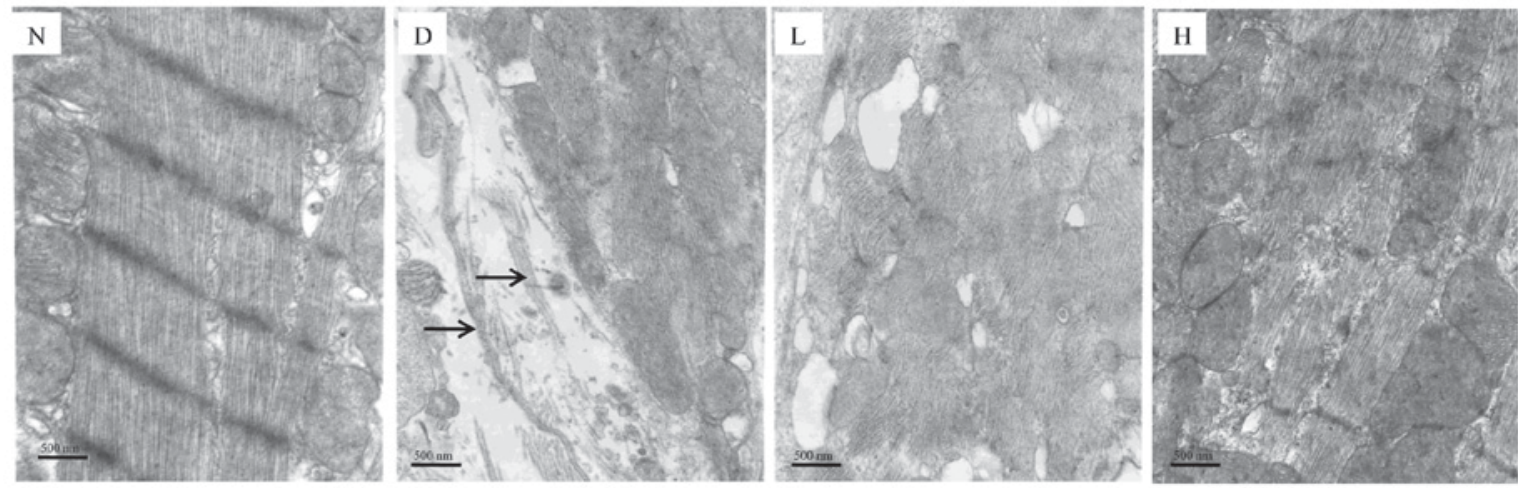

Figure 5. Differences in myocardium ultrastructure under transmission electron microscopy in the different groups. Arrows refer to collagen fibers in the D group. N, normal control group; D, diabetic control group; L, low-dose genistein treatment group; H, high-dose genistein treatment group. Scale bar, $500 \mathrm{~nm}$.
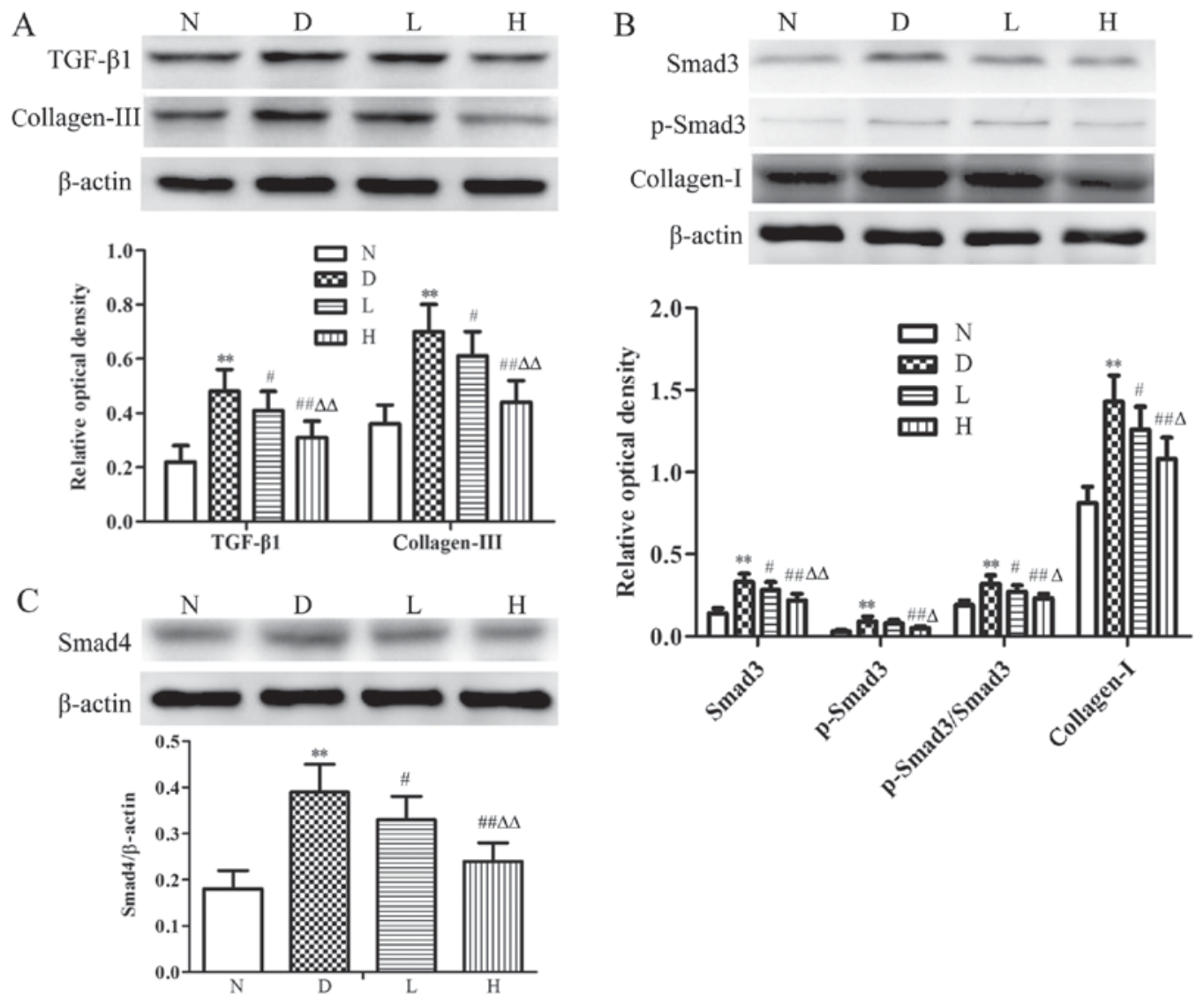

Figure 6. Protein expression of TGF- $\beta 1$, Smad3, p-Smad3, Smad4, collagen-I and collagen-III in myocardial tissue in the different groups. Representative western blotting and quantitative analysis of the (A) TGF- $\beta 1$, collagen-III, (B) Smad3, p-Smad3, collagen-I and (C) Smad4 protein expression ratio in the myocardial tissue of different groups. $\beta$-actin was used as a loading control. Data were expressed as the mean $\pm \operatorname{standard}$ deviation $(n=8) .{ }^{* *} \mathrm{P}<0.01$ vs. $\mathrm{N}$ group; ${ }^{\#} \mathrm{P}<0.05$ and ${ }^{\# \#} \mathrm{P}<0.01$ vs. $\mathrm{D}$ group; ${ }^{\Delta} \mathrm{P}<0.05$ and ${ }^{\Delta \Delta} \mathrm{P}<0.01$ vs. L group. $\mathrm{N}$, normal control group; $\mathrm{D}$, diabetic control group; $\mathrm{L}$, low-dose genistein treatment group; H, high-dose genistein treatment group; TGF- $\beta 1$, transforming growth factor- $\beta 1$; Smad, mothers against decapentaplegic homolog; p-, phosphorylated.

significantly increased $(\mathrm{P}<0.01)$ in the $\mathrm{D}$ group. In contrast to $\mathrm{D}$ group, there was no statistical difference in $\mathrm{p}$-Smad3 expression, the levels of myocardial TGF- $\beta 1, \mathrm{Smad} 3, \mathrm{p}-\mathrm{Smad} 3 / \mathrm{Smad} 3$, Smad4, collagen-I and collagen-III were decreased $(\mathrm{P}<0.05)$ in the L group; the levels of myocardial TGF- $\beta 1$, Smad3, p-Smad3, p-Smad3/Smad3, Smad4, collagen-I and collagen-III were significantly decreased $(\mathrm{P}<0.01)$ in the $\mathrm{H}$ group. Compared with the $\mathrm{L}$ group, the aforementioned indices were decreased $(\mathrm{P}<0.05, \mathrm{P}<0.01)$ in the $\mathrm{H}$ group (Fig. 6).

\section{Discussion}

DCM is one of the most common complications of diabetes, which major pathological characteristics are hypertrophy or hyperplasia in cardiomyocytes. Excessive deposition of myocardial interstitial collagen and myocardial fibrosis often leads to cardiac hypertrophy and heart dysfunction, which plays an important role in the occurrence and development of DCM (17). 
The results in the present study showed that compared with the $\mathrm{N}$ group, FBG, LVEDP and HW/BW were increased significantly in the D group, while LVSP and $\pm d p / d t_{\max }$ were decreased significantly, which indicated the heart dysfunction and cardiomyocyte hypertrophy in diabetic rats. In addition, there were histomorphological changes and ultrastructure damage in the D group. The serum CK-MB, LDH, TNF- $\alpha$, IL-1 $\beta$ and IL- 6 levels, Hyp content and the protein expression of collagen-I and collagen-III in the D group were significantly increased compared with the $\mathrm{N}$ group, which indicated that myocardial injury, inflammatory reaction and myocardial fibrosis were significantly aggravated in diabetic rats.

GEN is a type of plant estrogens, which exhibits antioxidant, anti-inflammatory and anti-apoptotic effects. GEN can prevent isoproterenol-induced cardiac hypertrophy in rats (18) and ameliorate adverse cardiac effects induced by arsenic trioxide through preventing cardiomyocytes apoptosis (19). In the present study, we investigated the protective effects of low- and high-dose GEN on myocardial tissue in diabetic rats. Compared with the D group, the data showed that, although there was no statistical difference in cardiac function in the $\mathrm{L}$ group, the cardiac diastolic and systolic functions were improved in the $\mathrm{H}$ group. In addition, $\mathrm{HW} / \mathrm{BW}$ and the levels of TNF- $\alpha$, IL- $1 \beta$ and IL- 6 were decreased in the L and H groups. It is suggested that GEN can alleviate myocardial hypertrophic changes and inflammatory reaction to improve cardiac function, which indicated that GEN has a protective effect in DCM.

In myocardial injury, $\mathrm{CK}-\mathrm{MB}$ and $\mathrm{LDH}$ are two specific indicators. CK-MB is a key enzyme in the energy metabolism of cardiomyocytes, and LDH is an important dehydrogenase in the process of anaerobic glycolysis (20). CK-MB and LDH activities were low in the serum under normal physiological conditions. When the myocardium injured and the cell membrane permeability changing, leakage of intracellular proteins such as CK-MB and LDH could occur. CK-MB and LDH activities were significantly increased in the serum, which indicated that the degree of myocardial injury was aggravated. Schmidt et al (21) reported that GEN can reduce LDH release and inhibit proliferation of malignant glioma cells by inhibiting protein tyrosine kinase activity. This study showed that compared with $\mathrm{N}$ group, serum $\mathrm{CK}-\mathrm{MB}$ and $\mathrm{LDH}$ activities were significantly increased in the $\mathrm{D}$ group. After treating diabetic rats with GEN, serum CK-MB and LDH activities were decreased in the $\mathrm{L}$ and $\mathrm{H}$ groups. The results suggested that GEN can alleviate myocardial injury through reducing CK-MB and LDH leakage in diabetic rats.

In addition, some studies have reported that GEN, which has anti-proliferative activity in many cell types and inhibits tyrosine kinases, may benefit the cardiovascular system. GEN can inhibit aortic smooth muscle cell proliferation in rat (22) and abolish nucleoside uptake by cardiac fibroblasts in vitro (23). Therefore, this raises the question as to the exact mechanism by which GEN exerts its cardioprotective effect in diabetic rat and whether the mechanism is associated with regulation of myocardial collagen expression.

Evidence from human and experimental models of DCM has implicated cardiac fibrosis as a strong pathological contributor (24,25). Cardiac fibrosis can increase left ventricle stiffness and decrease ventricular wall compliance, and these results in systolic and in particular diastolic dysfunction (26). Excess ECM, which is caused by an imbalance between synthesis and degradation, plays an important role in cardiac fibrosis. Therefore, the content of ECM can be used to assess the degree of myocardial fibrosis. In heart, the major components of ECM are interstitial collagens such as collagen-I and collagen-III. Collagen-I accounts for $80 \%$ of total collagen in the heart and the fiber is thick with good toughness and strong anti-stretch function; collagen-III accounts for $11 \%$ of total collagen and the fiber is thin with good stretch to maintain the heart elasticity. Therefore, cardiac dysfunction would happen when excessive deposition of these two collagens disrupts the structure of the heart. Compared with the $\mathrm{N}$ group, data showed that collagen-I and collagen-III protein expressions were significantly increased in diabetic rats, which verified that myocardial collagen content increased could aggravate the degree of fibrosis. In contrast to D group, the protein expression of collagen-I and collagen-III were significantly decreased in the $\mathrm{L}$ and $\mathrm{H}$ groups. We suggest that GEN exhibits cardioprotective effect through inhibiting the excessive production of myocardial collagen and alleviating myocardial fibrosis in diabetic rats.

TGF- $\beta 1$ is a key signaling molecule to induce cardiac fibrosis by activating the proliferation and collagen production of cardiac fibroblasts, and plays a significant role in the development and progression of ECM metabolism (27). On the one hand, TGF- $\beta 1$ can directly induce the activation of ECM gene transcription and high expression; on the other hand, TGF- $\beta 1$ can suppress the degradation of ECM by inhibiting matrix metalloproteinases and inducing tissue inhibitor of metalloproteinase, which may lead to a deterioration in myocardial injury and the occurrence and development of myocardial fibrosis (28).

Smads are pivotal intracellular nuclear effectors of TGF- $\beta 1$ family members (29). Ligand-induced activation of TGF- $\beta$ family receptors with intrinsic serine/threonine kinase activity triggers phosphorylation of receptor-regulated Smads. Of these, Smad 3 is phosphorylated by TGF- $\beta 1$, followed by binding with Smad4 to form a complex that translocates to the nucleus. This signaling cascade finally produces fibrotic mediators such as collagens (30,31). Many studies have found that the TGF- $\beta 1 / \mathrm{Smad} 3$ signaling pathway mediates a number of fibrotic diseases, such as hepatic fibrosis (32) and pulmonary fibrosis (33). Our data also showed that compared with the $\mathrm{N}$ group, the protein expression of TGF- $\beta 1, \mathrm{Smad} 3, \mathrm{p}-\mathrm{Smad} 3$ and Smad4 were significantly increased in the D group, this confirmed that the TGF- $\beta 1 / \operatorname{Smad} 3$ pathway was involved in myocardial fibrosis in diabetic rats. After treating diabetic rats with GEN, the results showed that the expression levels of TGF- $\beta 1$, Smad3, p-Smad3/Smad3 and Smad4 were decreased in the $\mathrm{L}$ and $\mathrm{H}$ groups, and this decrease was positively correlated with the dose of GEN. Thus, we suggest that GEN can inhibit the TGF- $\beta 1 / \mathrm{Smad} 3$ signaling pathway to regulate the collagens expression in DCM.

In conclusion, GEN can attenuate myocardial fibrosis in type 1 diabetic rats, and the underlying mechanism may be associated with the reduction of CK-MB and LDH leakage, inhibition of inflammatory reaction, and suppression of the TGF- $\beta 1 /$ Smad3 signaling pathway to regulate the collagens expression. 


\section{Acknowledgements}

The present study was supported by the Natural Science Research Project of the Education Commission of Anhui Province (KJ2017A216), the Natural Science Research Project of Bengbu Medical College (BYKY1621ZD), and the National Undergraduate Innovation and Entrepreneurship Program (201510367009), China.

\section{References}

1. Mohan V, Seedat YK and Pradeepa R: The rising burden of diabetes and hypertension in southeast Asian and African regions: Need for effective strategies for prevention and control in primary health care settings. Int J Hypertens 2013: 409083, 2013.

2. Ward ML and Crossman DJ: Mechanisms underlying the impaired contractility of diabetic cardiomyopathy. World J Cardiol 6: 577-584, 2014.

3. Aneja A, Tang WH, Bansilal S, Garcia MJ and Farkouh ME: Diabetic cardiomyopathy: Insights into pathogenesis, diagnostic challenges and therapeutic options. Am J Med 121: 748-757, 2008.

4. Miki T, Yuda S, Kouzu H and Miura T: Diabetic cardiomyopathy: Pathophysiology and clinical features. Heart Fail Rev 18 149-166, 2013.

5. Hu X, Bai T, Xu Z, Liu Q, Zheng Y and Cai L: Pathophysiological fundamentals of diabetic cardiomyopathy. Compr Physiol 7: 693-711, 2017.

6. Fujiu K, Wang J and Nagai R: Cardioprotective function of cardiac macrophages. Cardiovasc Res 102: 232-239, 2014.

7. Cunnington RH, Nazari M and Dixon IM: c-Ski, Smurf2 and Arkadia as regulators of TGF-beta signaling: New targets for managing myofibroblast function and cardiac fibrosis. Can J Physiol Pharmacol 87: 764-772, 2009.

8. Liu X, Liang E, Song X, Du Z, Zhang Y and Zhao Y: Inhibition of Pin1 alleviates myocardial fibrosis and dysfunction in STZ-induced diabetic mice. Biochem Biophys Res Commun 479: 109-115, 2016.

9. Zhang Y, Zhang L, Zhang Y, Xu JJ, Sun LL and Li SZ: The protective role of liquiritin in high fructose-induced myocardial fibrosis via inhibiting NF- $\mathrm{BB}$ and MAPK signaling pathway. Biomed Pharmacother 84: 1337-1349, 2016.

10. Patisaul HB and Jefferson W: The pros and cons of phytoestrogens. Front Neuroendocrinol 31: 400-419, 2010.

11. Guo TL, Germolec DR, Zheng JF, Kooistra L, Auttachoat W, Smith MJ, White KL and Elmore SA: Genistein protects female nonobese diabetic mice from developing type 1 diabetes when fed a soy- and alfalfa-free diet. Toxicol Pathol 43: 435-448, 2015.

12. Elmarakby AA, Ibrahim AS, Faulkner J, Mozaffari MS, Liou GI and Abdelsayed R: Tyrosine kinase inhibitor, genistein, reduces renal inflammation and injury in streptozotocin-induced diabetic mice. Vascul Pharmacol 55: 149-156, 2011.

13. Kim MJ and Lim Y: Protective effect of short-term genistein supplementation on the early stage in diabetes-induced renal damage. Mediators inflamm 2013: 510212, 2013.

14. Gupta SK, Dongare S, Mathur R, Mohanty IR, Srivastava S, Mathur S and Nag TC: Genistein ameliorates cardiac inflammation and oxidative stress in streptozotocin-induced diabetic cardiomyopathy in rats. Mol Cell Biochem 408: 63-72, 2015.

15. Ganai AA and Husain M: Genistein attenuates D-GalN induced liver fibrosis/chronic liver damage in rats by blocking the TGF- $\beta$ /Smad signaling pathways. Chem Biol Interact 261: 80-85, 2017.

16. Sung MJ, Kim DH, Jung YJ, Kang KP, Lee AS, Lee S, Kim W, Davaatseren M, Hwang JT, Kim HJ, et al: Genistein protects the kidney from cisplatin-induced injury. Kidney Int 74: 1538-1547, 2008.
17. Kayama Y, Raaz U, Jagger A, Adam M, Schellinger IN Sakamoto M, Suzuki H, Toyama K, Spin JM and Tsao PS: Diabetic cardiovascular disease induced by oxidative stress. Int J Mol Sci 16: 25234-25263, 2015.

18. Maulik SK, Prabhakar P, Dinda AK and Seth S: Genistein prevents isoproterenol-induced cardiac hypertrophy in rats. Can J Physiol Pharmacol 90: 1117-1125, 2012.

19. Fan Y, Wang C, Zhang Y, Hang P, Liu Y, Pan Z, Wang N and Du Z: Genistein ameliorates adverse cardiac effects induced by arsenic trioxide through preventing cardiomyocytes apoptosis. Cell Physiol Biochem 31: 80-91, 2013.

20. Yu Y, Jia XJ, Zong QF, Zhang GJ, Ye HW, Hu J, Gao Q and Guan SD: Remote ischemic postconditioning protects the heart by upregulating ALDH2 expression levels through the PI3K/Akt signaling pathway. Mol Med Rep 10: 536-542, 2014.

21. Schmidt F, Knobbe CB, Frank B, Wolburg H and Weller M: The topoisomerase II inhibitor, GEN, induces G2/M arrest and apoptosis in human malignant glioma cell lines. Oncol Rep 19: 1061-1066, 2008

22. Yu JY, Lee JJ, Lim Y, Kim TJ, Jin YR, Sheen YY and Yun YP: Genistein inhibits rat aortic smooth muscle cell proliferation through the induction of p27kip1. J Pharmacol Sci 107: 90-98, 2008.

23. Pillai MS and Shivakumar K: Genistein abolishes nucleoside uptake by cardiac fibroblasts. Mol Cell Biochem 332: 121-125, 2009.

24. Kain V, Kumar S and Sitasawad SL: Azelnidipine prevents cardiac dysfunction in streptozotocin-diabetic rats by reducing intracellular calcium accumulation, oxidative stress and apoptosis. Cardiovasc Diabetol 10: 97, 2011.

25. Li CJ, Lv L, Li H and Yu DM: Cardiac fibrosis and dysfunction in experimental diabetic cardiomyopathy are ameliorated by alpha-lipoic acid. Cardiovasc Diabetol 11: 73, 2012.

26. Asbun $\mathrm{J}$ and Villarreal FJ: The pathogenesis of myocardial fibrosis in the setting of diabetic cardiomyopathy. J Am Coll Cardiol 47: 693-700, 2006.

27. Pan Z, Zhao W, Zhang X, Wang B, Wang J, Sun X, Liu X, Feng S, Yang B and Lu Y: Scutellarin alleviates interstitial fibrosis and cardiac dysfunction of infarct rats by inhibiting TGF- $\beta 1$ expression and activation of p38-MAPK and ERK1/2. Br J Pharmacol 162: 688-700, 2011.

28. Cutroneo KR: TGF-beta-induced fibrosis and SMAD signaling: Oligo decoys as natural therapeutics for inhibition of tissue fibrosis and scarring. Wound Repair Regen 15 (Suppl 1): S54-S60, 2007.

29. Itoh S, Itoh F, Goumans MJ and Ten Dijke P: Signaling of transforming growth factor-beta family members through Smad protein. Eur J Biochem 267: 6954-6967, 2000.

30. Hata $A$ and Chen YG: TGF- $\beta$ signaling from receptors to smads. Cold Spring Harb Perspect Biol 8: a002261, 2016.

31. Ko JW, Shin NR, Park SH, Kim JS, Cho YK, Kim JC, Shin IS and Shin DH: Pine bark extract $\left(\right.$ Pycnogenol $\left.^{\circledR}\right)$ suppresses cigarette smoke-induced fibrotic response via transforming growth factor- $\beta 1 /$ Smad family member $2 / 3$ signaling. Lab Anim Res 33 : 76-83, 2017

32. Xu F, Liu C, Zhou D and Zhang L: TGF- $\beta /$ SMAD pathway and its regulation in hepatic fibrosis. J Histochem Cytochem 64: 157-167, 2016.

33. Jeon WY, Shin IS, Shin HK, Jin SE and Lee MY: Aqueous extract of gumiganghwal-tang, a traditional herbal medicine, reduces pulmonary fibrosis by transforming growth factor- $\beta 1 / \mathrm{Smad}$ signaling pathway in murine model of chronic asthma. PLoS One 11: e0164833, 2016.

This work is licensed under a Creative Commons Attribution-NonCommercial-NoDerivatives 4.0 International (CC BY-NC-ND 4.0) License. 